\title{
A GREEN, LARGE SCALE SYNTHESIS OF FENOPROFEN CALCIUM DIHYDRATE WITH SIMPLE CALCIUM (II) CARBONATE AND WATER
}

\author{
S. Venkat Rao ${ }^{1, \bowtie}$, Vamsi Krishna Potluri ${ }^{1}$ and Rameshbabu Potluri ${ }^{1}$ \\ ${ }^{1}$ R\&D Center (A DSIR approved facility) SMS Pharmaceuticals Ltd., Survey No.189, 190, \\ Gagillapur (V), Hyderabad-500047, and India. \\ ${ }^{\square}$ Corresponding Author: venkat@smspharma.com
}

\begin{abstract}
The main objective of this research is to deliver a large-scale manufacturing procedure by using eco-friendly solvents or green solvents. The core invention of this research is fenoprofen calcium complex preparation with nonchlorinated calcium salt known as Calcium carbonate $\left(\mathrm{CaCO}_{3}\right)$ in aqueous media without using any organic solvent. This attempt has succeeded without using prior art calcium salt reagents like Calcium chloride $\left(\mathrm{CaCl}_{2}\right)$ and $\mathrm{Calcium}$ hydroxide $\left(\mathrm{Ca}(\mathrm{OH})_{2}\right)$ and these reagents were used with the combination of organic solvents like ethanol or Acetone by earlier researchers. This article will give an eco-friendly process and improved quality material of Fenoprofen calcium dihydrate as per ICH guidelines.

Keywords: Fenoprofen calcium dihydrate, Green synthesis, Calcium salt formation, Calcium carbonate, Water and without organic solvent
\end{abstract}

RASĀYAN J. Chem., Vol. 14, No.2, 2021

\section{INTRODUCTION}

The generic drug substance, which is used for the treatment of symptomatic relief for rheumatoid arthritis, osteoarthritis, and mild to moderate pain, is Fenoprofen calcium dihydrate (1). The author attempted a new method of synthesis to make calcium salt of Fenoprofen with calcium carbonate instead of using other calcium reagents and this attempt was made with green solvent water. The majority of the prior art procedures were reported in organic solvents like Acetone, Ethanol etc.

The author optimized the process in all stages by incorporating commercially available reagents, which are feasible against the mass production of compound 1 . Here in scheme 2 of the innovator route which was described the bromination of secondary alcohol with phosphorous tribromide and salt formation was made with stepwise active metal booster methodology with sodium hydroxide ${ }^{1}$. Very few pieces of literature were available for the synthesis of chiral pure fenoprofen calcium ${ }^{2}$ and various fenoprofen metal complex compounds preparations to enhance the pharmacological activity of Fenoprofen ${ }^{3}$.

We developed a single-step salt formation process to reduce the cost and completely removed expensive phosphorous tribromide by substituting a highly inexpensive halogenating reagent Thionyl chloride as described in Scheme-1 of compound 1. It is a commercially scalable process that competes with the market price and in line with all the regulatory specifications requirements.

The main invention in this process is Calcium salt formation with calcium carbonate without organic solvents and hence this final process is so-called green synthesis. The other literature reagents like calcium chloride and calcium hydroxide were corrosive, bit expensive than calcium carbonate.

\section{EXPERIMENTAL}

Synthesis of 1-(3-phenoxyphenyl) ethanone (6)

In a clean and dry round bottom flask $500.0 \mathrm{gm}$ of compound 8 was dissolved in $3000.0 \mathrm{~mL}$ of $\mathrm{N}, \mathrm{N}-$ Dimethylformamide under gentle stirring at room temperature (RT). After 10 minutes of stirring it was added $3000.0 \mathrm{gm}$ of anhydrous potassium carbonate, $1000 \mathrm{gm}$ of compound 7 and $150.0 \mathrm{gm}$ of copper powered, then the reaction mixture temperature was heated and maintained for 8 hours at $150-155^{\circ} \mathrm{C}$ until its starting material get complies over HPLC monitoring (starting material NMT 2.0\%).

Rasayan J. Chem., 14(2), 1035-1040(2021)

http://dx.doi.org/10.31788/ RJC.2021.1426037

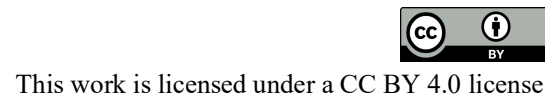


RASĀYAN J. Chem.

Vol. 14 | No. 2 |1035-1040| April - June | 2021

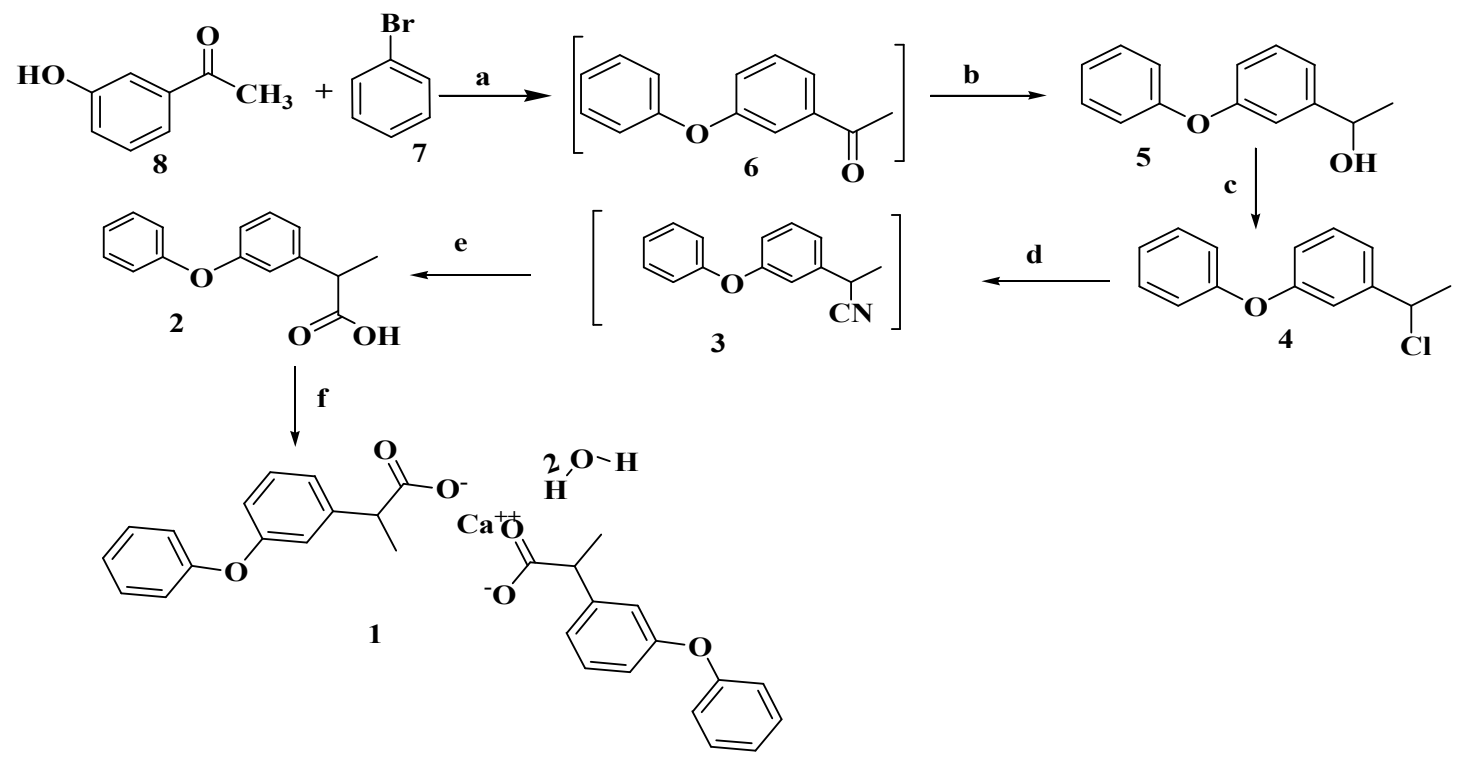

a) K2CO3, DMF, O-xylene , NaOH, Conc.HCl, Cu ;b)NaBH4, $\mathrm{HCl}$, MeoH, $\mathrm{MDC}$;c). $\mathrm{SOCl}_{2}, \mathrm{MDC} \mathrm{NaHCO}_{3}$ ;d)NaCN, DMSO, $\mathrm{H}_{2} \mathrm{O}$, MDC; e) KOH, EtOH, $\mathrm{NaOH}$, EtoAC, MDC ;f) $\mathrm{CaCO}_{3}$, Water Scheme-1: Proposed Route of Synthesis of Compound 1

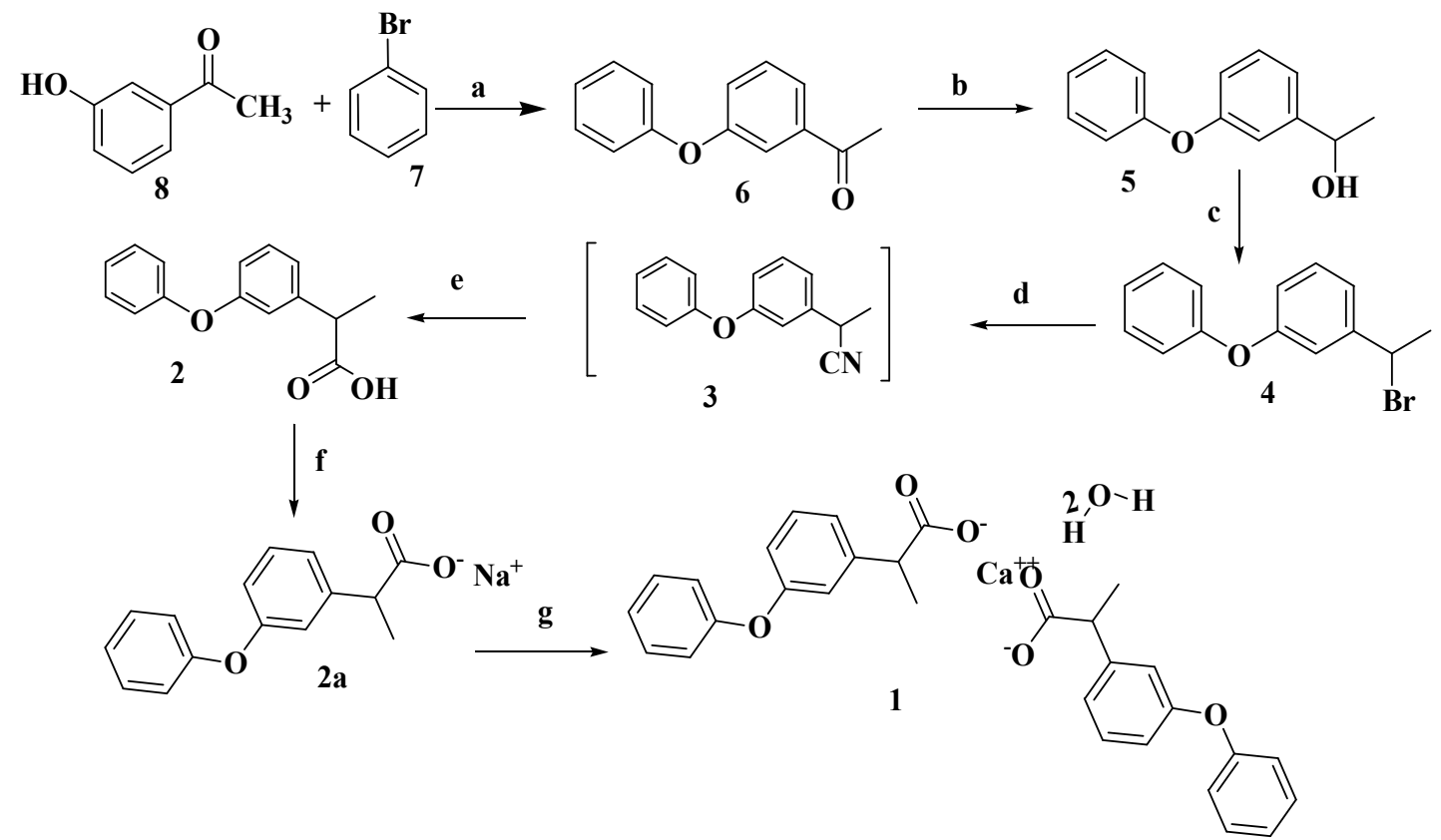

a) $\mathrm{K2CO3,} \mathrm{DMF,} \mathrm{,Cu} \mathrm{;b)NaBH4} \mathrm{;c).} \mathrm{PBr3}$;d)NaCN, DMSO e) H2O, H+ ;f): $\mathrm{NaOH}$, water g) $\mathrm{CaCl}_{2}$, Acetone Scheme-2: Prior Art Literature/ Innovator Route of Synthesis

The reaction mixture was cooled to $25-35^{\circ} \mathrm{C}$ (RT) and filter the residual potassium carbonate, copper through celite bed. The resulting solution was distilled under reduced pressure; the obtained residue was diluted with O-xylene $(5000.0 \mathrm{~mL})$. The organic layer was washed twice with $5 \%$ Hydrochloric acid ( $2 \mathrm{x}$ $750.0 \mathrm{~mL}$ ) followed by $5 \%$ Sodium hydroxide $(2 \times 750.0 \mathrm{~mL})$ and finally washed with saturated sodium chloride. After removal of O-xylene under vacuum, the resulting crude oily mass yield of compound6 was reported as $720.0 \mathrm{gm}(87.03 \%)$ with purity NLT $98.0 \%$ and any other impurity content NMT $1.0 \%$. 
RASĀYAN J. Chem.

Vol. 14 | No. 2 |1035-1040| April - June | 2021

1HNMR $\left(\mathrm{CDCl}_{3}\right): \delta 2.57(\mathrm{~s}, 3 \mathrm{H}) ; \delta 7.03(\mathrm{~d}, 2 \mathrm{H}) ; \delta 7.14(\mathrm{t}, 1 \mathrm{H}) ; \delta 7.19-7.22(\mathrm{dd}, 1 \mathrm{H}) ; \delta 7.36(\mathrm{t}, 2 \mathrm{H}) ; \delta$ $7.40(\mathrm{t}, 1 \mathrm{H}) ; \delta 7.58(\mathrm{bs}, 1 \mathrm{H}) ; \delta 7.67(\mathrm{dd}, 1 \mathrm{H}) ;{ }^{13} \mathrm{C}$ NMR: 26.63, 117.98, 119.02, 123.21, 129.86, 138.77 , 156.50, 157.64, 197.32; FT-IR $\left(\mathrm{Cm}^{-1}\right): 3066.23,3039.801686 .05,1072.46,1162.34$, Mass $\left(\mathrm{M}^{+\mathrm{H}}\right): 213.2$ $\left(\mathrm{M}^{+}: 212.34\right)$.

\section{Synthesis of 1-(3-phenoxyphenyl) ethanol (5)}

$700.0 \mathrm{gm}$ of compound 6 was dissolved in $3500.0 \mathrm{~mL}$ of methanol under gentle stirring and then added $93.59 \mathrm{gm}$ of Sodium borohydride portion wise at $0-5^{\circ} \mathrm{C}$. Stirred the reaction mass for $2-3$ hours at $0-5^{0} \mathrm{C}$, reaction monitored by HPLC, once reaction complies and then reaction mass quenched in precooled water solution and $\mathrm{pH}$ adjusted $6 \mathrm{~N}$ Hydrochloric acid. The resulting reaction mass was extracted with methylene chloride $(3 \mathrm{X} 3000.0 \mathrm{~mL})$. The combined organic layers were washed with saturated sodium chloride and the dried organic layer was removed under reduced pressure. The obtained yield was reported 750.0 gm $(98.0 \%)$ with purity NLT $99.0 \%$ and any other impurity NMT $1.0 \%$.

1HNMR $\left(\mathrm{CDCl}_{3}\right): \delta 1.47-1.49(\mathrm{~d}, 3 \mathrm{H}) ; \delta 1.77(\mathrm{~d}, 1 \mathrm{H}) ; \delta$ 4.85-4.90(m, $\left.1 \mathrm{H}\right) ; \delta 6.89-6.91(\mathrm{dd}, 1 \mathrm{H}) ; 6.99-7.02$ $(\mathrm{dd}, 2 \mathrm{H}), \delta 7.05(\mathrm{t}, 1 \mathrm{H}) ; \delta$ 7.09-7.12 (m, 2H); $\delta$ 7.28-7.36 (m, 3H); 13CNMR: 25.16, 70.05, 115.79, 117.64, 118.91, 120.10 123.27, 129.73, 129.77, 147.97, 157.05, 157..43; FT-IR( $\left(\mathrm{Cm}^{-1}\right): 3367.29,3065.49$, 3039.46, 1163.85, 1071.70; Mass $\left(\mathrm{M}^{+\mathrm{H}}\right): 214.2\left(\mathrm{M}^{+}: 214.26\right)$.

\section{Synthesis of 1-(3-(1-Chloroethyl) Phenoxy) benzene (4)}

In a dry round bottom flask $700.0 \mathrm{gm}$ of compound 5 in $4000.0 \mathrm{~mL}$ of Methylene chloride and then added $300 \mathrm{gm}$ of Thionyl chloride dropwise at room temperature. Slowly raise the temperature to reflux for 4 to 5 hours, once TLC complies then quench the reaction mass into the water and separate the organic layer. The resulting organic layer is distilled out to get compound 4. Yield reported: $680.0 \mathrm{gm}$; 1HNMR $\left(\mathrm{CDCl}_{3}\right): \delta 1.83(\mathrm{~d}, 3 \mathrm{H}) ; \delta 5.01-5.06(\mathrm{~m}, 1 \mathrm{H}) ; \delta 6.90-6.93(\mathrm{dd}, 1 \mathrm{H}) ; \delta 7.01(\mathrm{~d}, 2 \mathrm{H}) ; \delta 7.08-7.14(\mathrm{~m}, 3 \mathrm{H}) ; \delta$ 7.25-7.36(m, 3H); 13CNMR: 26.38, 58.11, 116.86, 118.95, 121.15, 123.43, 129.75, 129.86, 144.74, 156.77, 157.39; FT-IR( $\left.\mathrm{Cm}^{-1}\right): 3063.89,3039.90,1163.22,693.15$; Mass $\left(\mathrm{M}^{-2 \mathrm{H}}\right): 230.1\left(\mathrm{M}^{+}: 232.71\right)$.

\section{Synthesis of 2-(3-phenoxyphenyl) ropane nitrile (3)}

In a clean round bottom flask $600.0 \mathrm{gm}$ of compound 4 was dissolved in $2500.0 \mathrm{~mL}$ of dimethylsulfoxide followed $159.12 \mathrm{gm}$ of sodium nitrile is added portion-wise. The resulting solution was heated to 70-75 ${ }^{0} \mathrm{C}$ and maintain for 6.0 hours until its starting materials gets completed. Once the reaction complies then is quenched in ice-cooled water and extracted with methylene chloride $(3 \mathrm{X} 1000 \mathrm{~mL})$. The combined organic layers were washed with saturated sodium chloride solution and then dried over sodium sulfate. The organic layer was distilled to afford compound 3 as a light yellow oil with 650 gm of yield. FT-IR $\left(\mathrm{Cm}^{-1}\right): 3064.66,3040.21,2986.75,2938.83,2242.48,1163.58$, and 1210.03

\section{Synthesis of 2-(3-phenoxyphenyl)propanoic acid (2)}

In a $3 \mathrm{~L}$ round bottom flask fitted with a reflux condenser and gentle stirrer $600.00 \mathrm{gm}$ of compound 3 was taken in a mixture of $600 \mathrm{ml}$ of Ethanol and $900 \mathrm{~mL}$ of $50 \%$ potassium carbonate under vigorous stirring at room temperature. Heat the reaction mass to $95^{\circ} \mathrm{C}$ and maintain it for 6-7 hours, after completion of the reaction cool the reaction mass to room temperature and then $\mathrm{pH}$ adjusted to 2 with $6 \mathrm{~N}$ Hydrochloride. The acidic mass was extracted with Ethyl acetate $(3 \mathrm{X} 1200 \mathrm{~mL})$, the combined organic layer was washed with saturated sodium chloride and dried over sodium sulfate. Remove the solvent to afford $550 \mathrm{gm}$ of compound 2 as a light yellow oil with purity NLT 99.0\%. 1HNMR $\left(\mathrm{CDCl}_{3}\right): \delta 1.48(\mathrm{~d}, 3 \mathrm{H}) ; \delta 3.71$ (q, $1 \mathrm{H}) ; \delta$ 6.85-6.89(dd, $1 \mathrm{H}) ; \delta$ 7.69-7.01 (d, 2H); $\delta$ 7.04-7.11(m, 3H); $\delta$ 7.22-7.34(m, 3H), $\delta 10.42(\mathrm{~s}, 1 \mathrm{H}) ;$ 13CNMR: $18.00,45.18,117.46,118.20,118.94,122.33,123.35,129.74,129.85,141.63,156.89,157.45$, 180.54; FT-IR $\left(\mathrm{Cm}^{-1}\right): 3064.29,3039.67,2982.13,2938.52,1711.80,1163.79,1072.53,1244.51$; Mass $\left(\mathrm{M}^{-\mathrm{H}}\right): 241.1\left(\mathrm{M}^{+}: 242.27\right)$.

\section{Synthesis of Calcium 2-(3-phenoxyphenyl) propanoate hydrate (1)}

In a round bottom flask $500.00 \mathrm{gm}$ of compound 2 (Fenoprofen) was dissolved in $2500.0 \mathrm{~mL}$ of water and $165.25 \mathrm{gm}$ of Calcium carbonate was added potion wise under gentle stirring. Heat the reaction mass temperature to $95^{\circ} \mathrm{C}$. Maintain the reaction temperature for 3-4 hours until the reaction complies with TLC. 
RASĀYAN J. Chem.

Vol. 14 | No. 2 |1035-1040| April - June | 2021

Brukex NMR $400 M{ }^{2}$
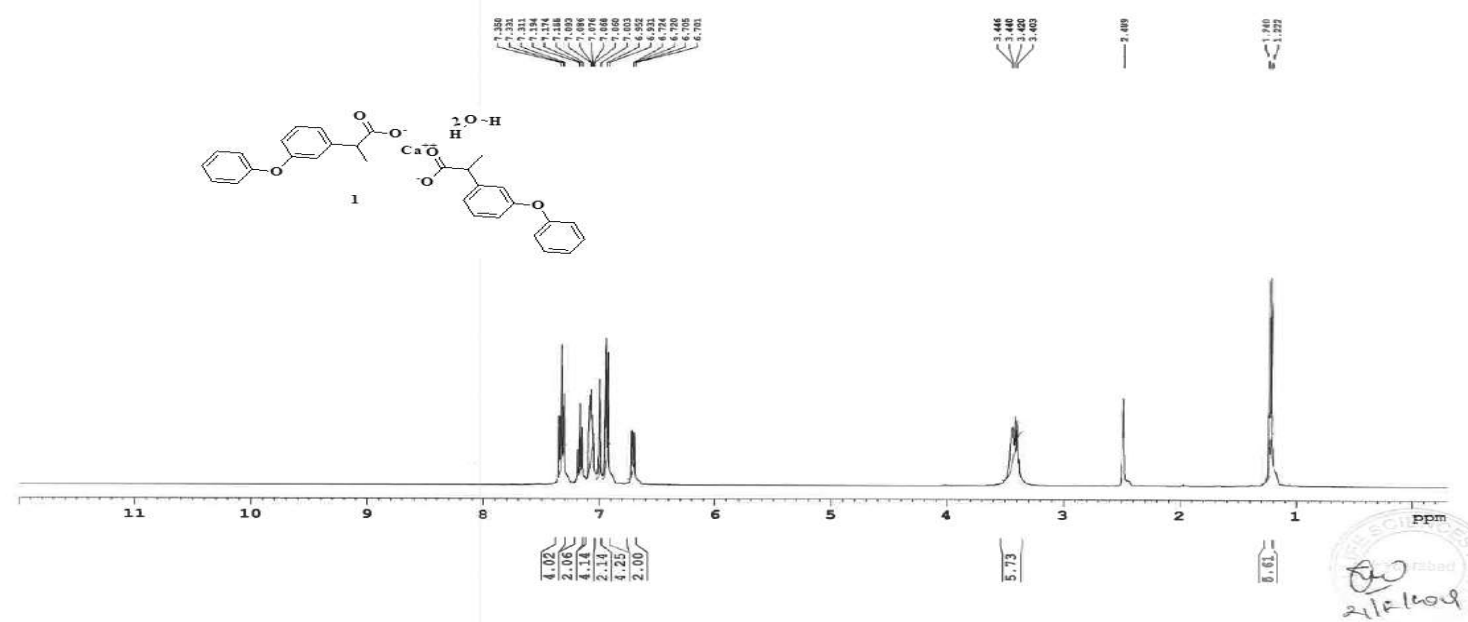

Fig.-1: 1H NMR of Compound 1
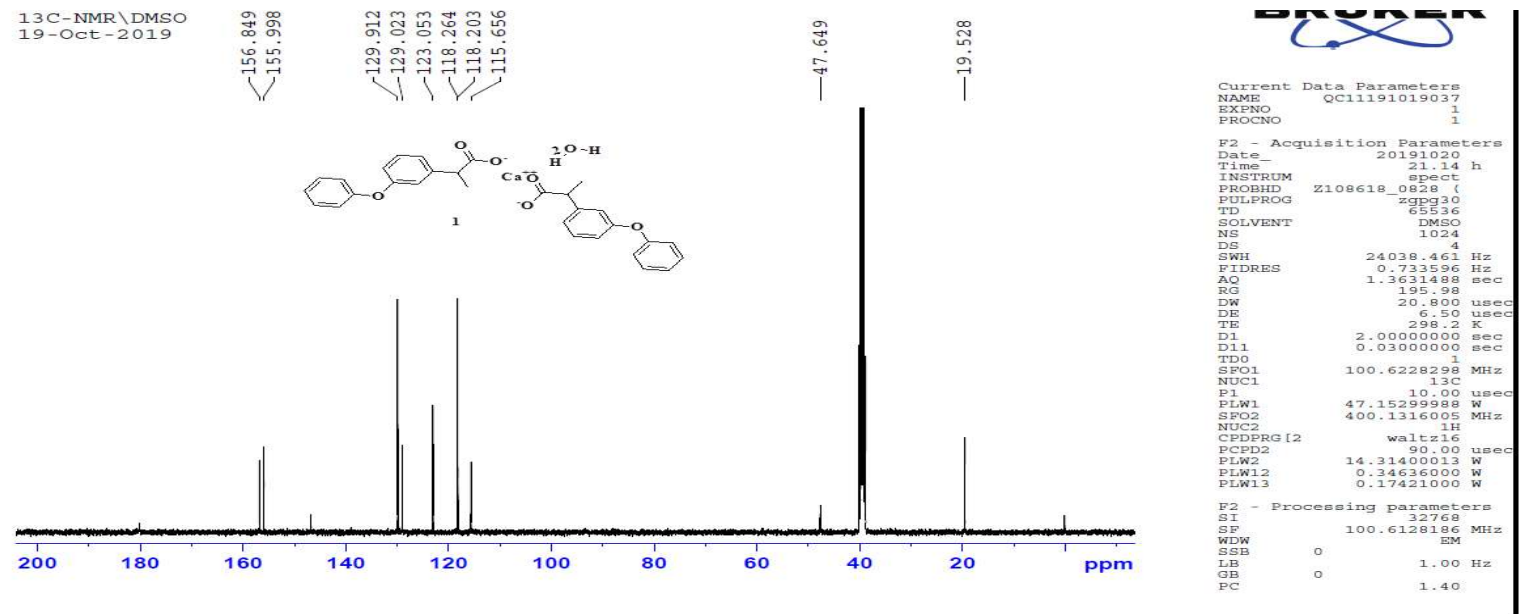

Fig.-2: 13CNMR of Compound 1

Date: Monday, 16 December, 2019

Time: 16:35 India Standard Time

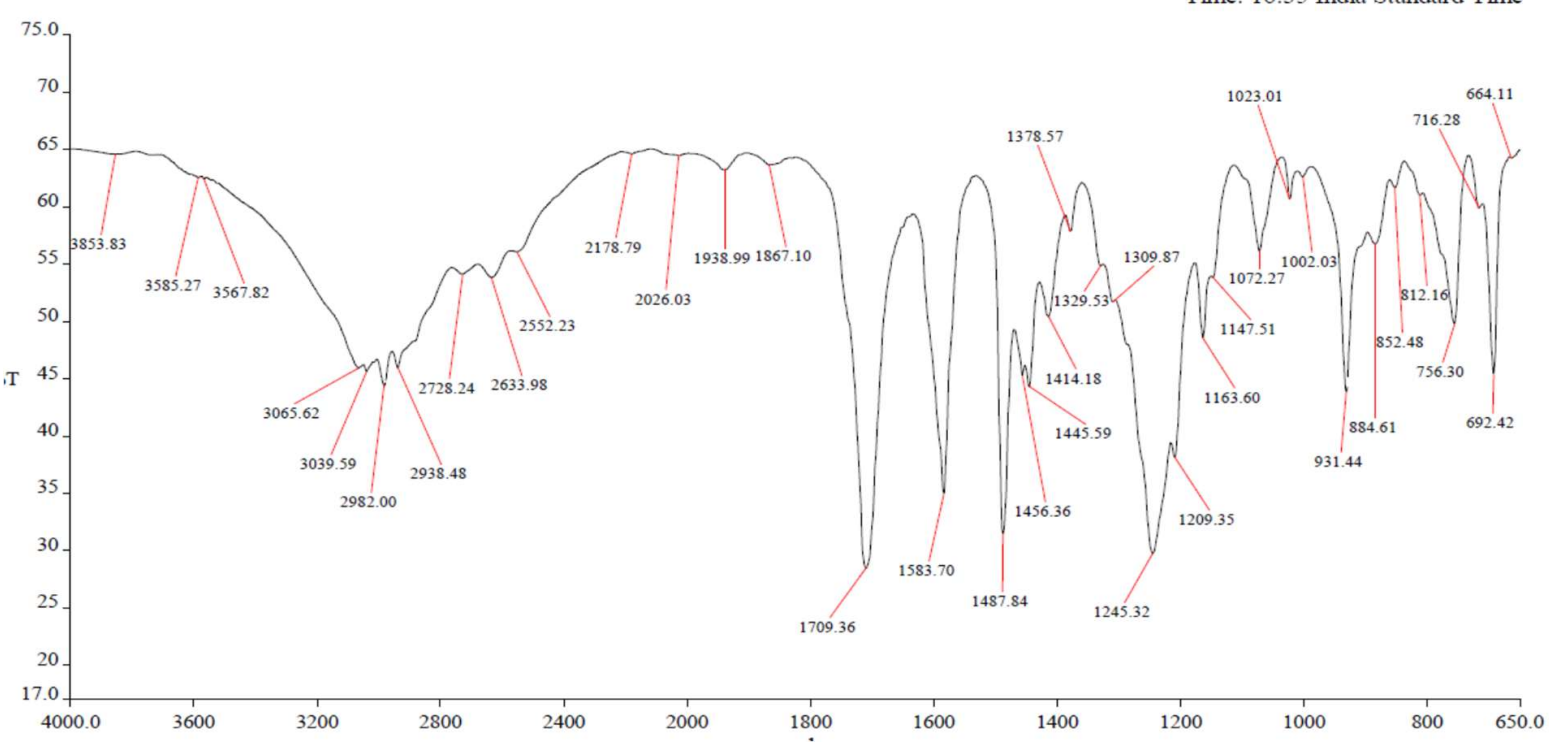

Fig.-3: FT-IR of Compound 1 
RASĀYAN J. Chem.

Vol. 14 | No. 2 |1035-1040| April - June | 2021

Once the reaction complies with TLC cool the reaction temperature to $25^{\circ} \mathrm{C}$ and then further cool to 10 $15^{\circ} \mathrm{C}$ under gentle stirring. Maintain the mass temperature for 45 minutes at $10-15^{\circ} \mathrm{C}$. The resulting white precipitate was filtered through the Buckner funnel and the filtered cake was washed with cool water. The wet material was subjected for drying at $75^{\circ} \mathrm{C}$ and afford $550 \mathrm{gm}$ of Fenoprofen calcium dihydrate with purity NLT 99.0\%, any other impurity NMT 0.1\%.1HNMR $\left(\mathrm{CDCl}_{3}\right): \delta 1.23(\mathrm{~d}, 3 \mathrm{H}) ; \delta 3.40(\mathrm{~m}, 1 \mathrm{H}) ; \delta$ $6.70(\mathrm{~d}, 1 \mathrm{H}) ; \delta 16.93-6.95(\mathrm{~d}, 2 \mathrm{H}) ; \delta 6.99(\mathrm{~s}, 1 \mathrm{H}) ; \delta$ 7.06-7.07 (t, 2H); $\delta$ 7.15-7.19 (t, $1 \mathrm{H}) ; \delta$ 7.31-7.35 (t, 2H); 13CNMR: 19.54, 47.60, 115.67, 118.26, 123.05, 123.10, 129.03, 129.91, 146.74, 156.00, 156.88, 180.31; FT-IR $\left(\mathrm{Cm}^{-1}\right): 3066.54,3037.84,2978.58,1420.16,1442.90,1162.79,1245.75$; $\quad$ Mass $\left(\mathrm{M}^{-\mathrm{H}}\right)$ : $241.13\left(\mathrm{M}^{+}: 242.27\right)$.

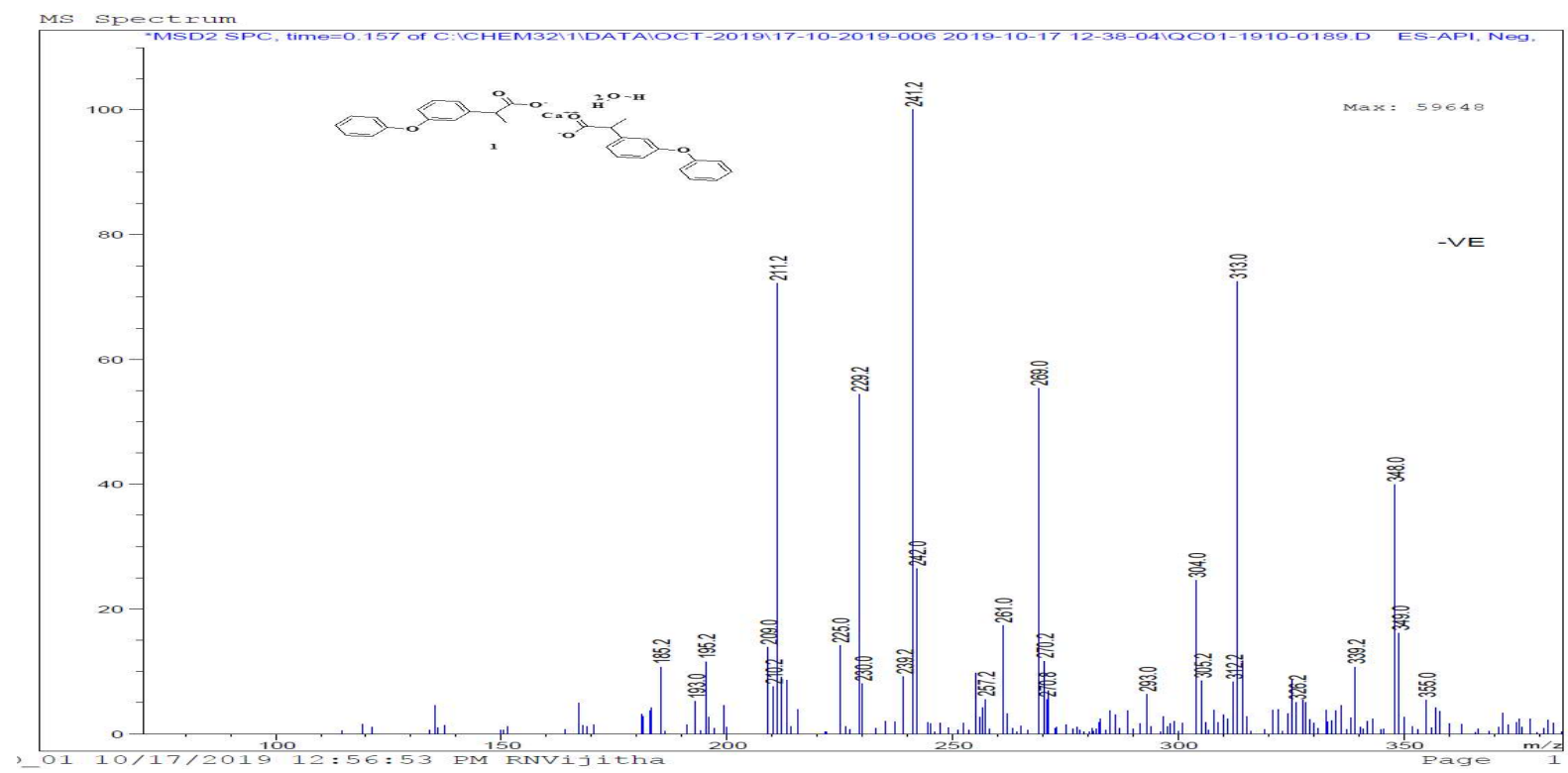

Fig.-4: Mass Spectra of Compound 1

Fenoprofen Calcium Dihydrate BNo-FPN-VII-009 (Reg No-D-A21900649)

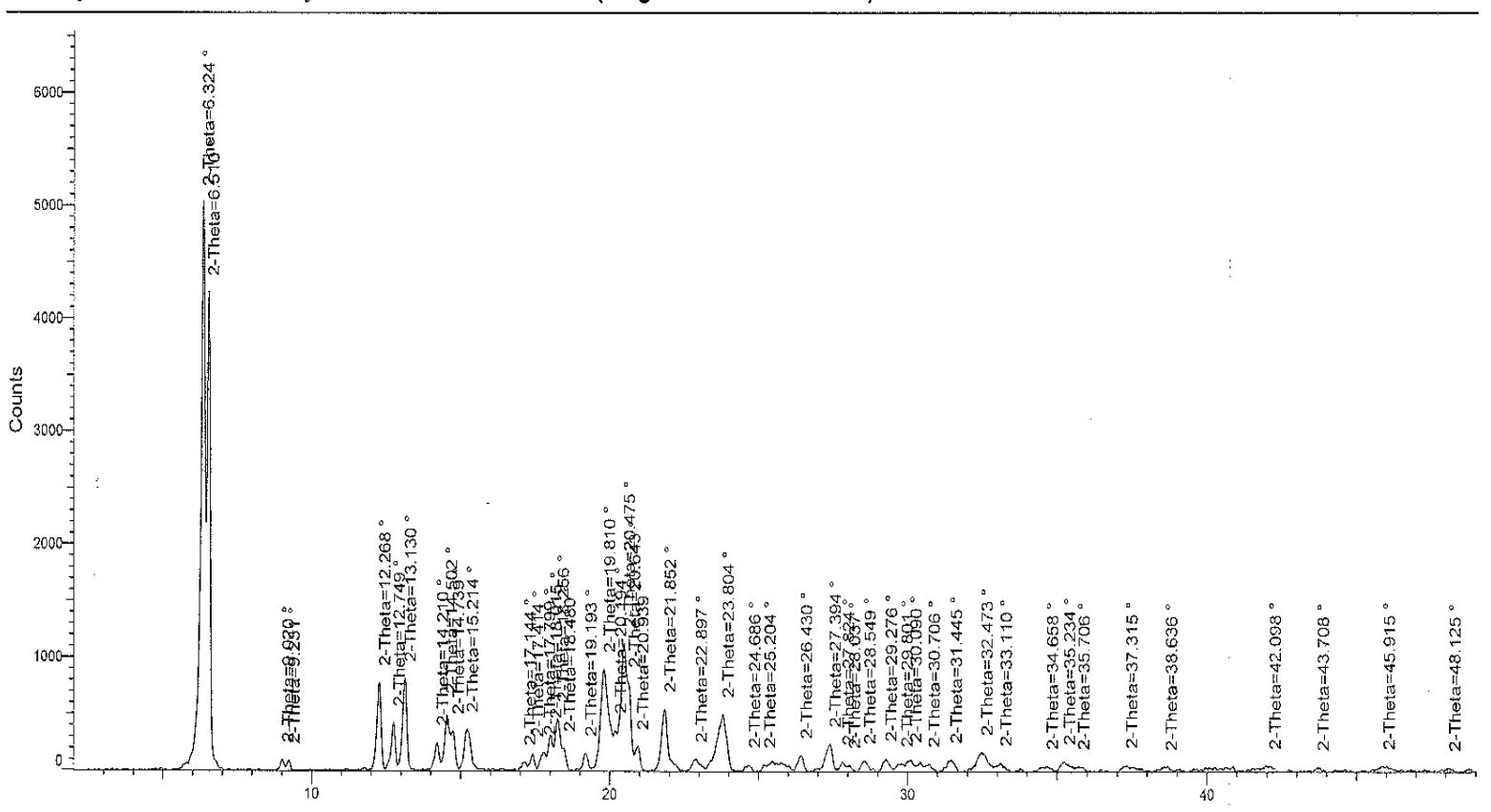

Fig.-5: PXRD of Compound 1

1039 
RASĀYAN J. Chem.

Vol. 14 | No. 2 |1035-1040| April - June | 2021

SMS Pharmaceuticals Limited:R\&D Center

Sample Information

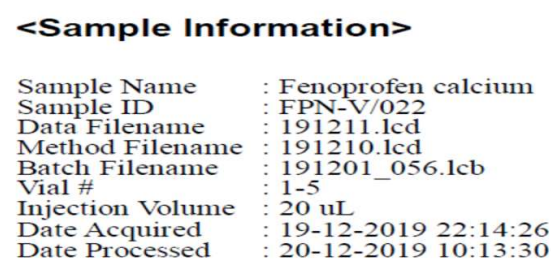

$191211.1 \mathrm{~cd}$

$\begin{array}{ll}\text { Sample Type } & : \text { Unknown } \\ \text { Acquired by } & : \text { Bhanovri Mohan }\end{array}$

Processed by $\quad$ : Ravi teja

<Chromatogram>

$\mathrm{mv}$

$191211.1 \mathrm{~cd}$
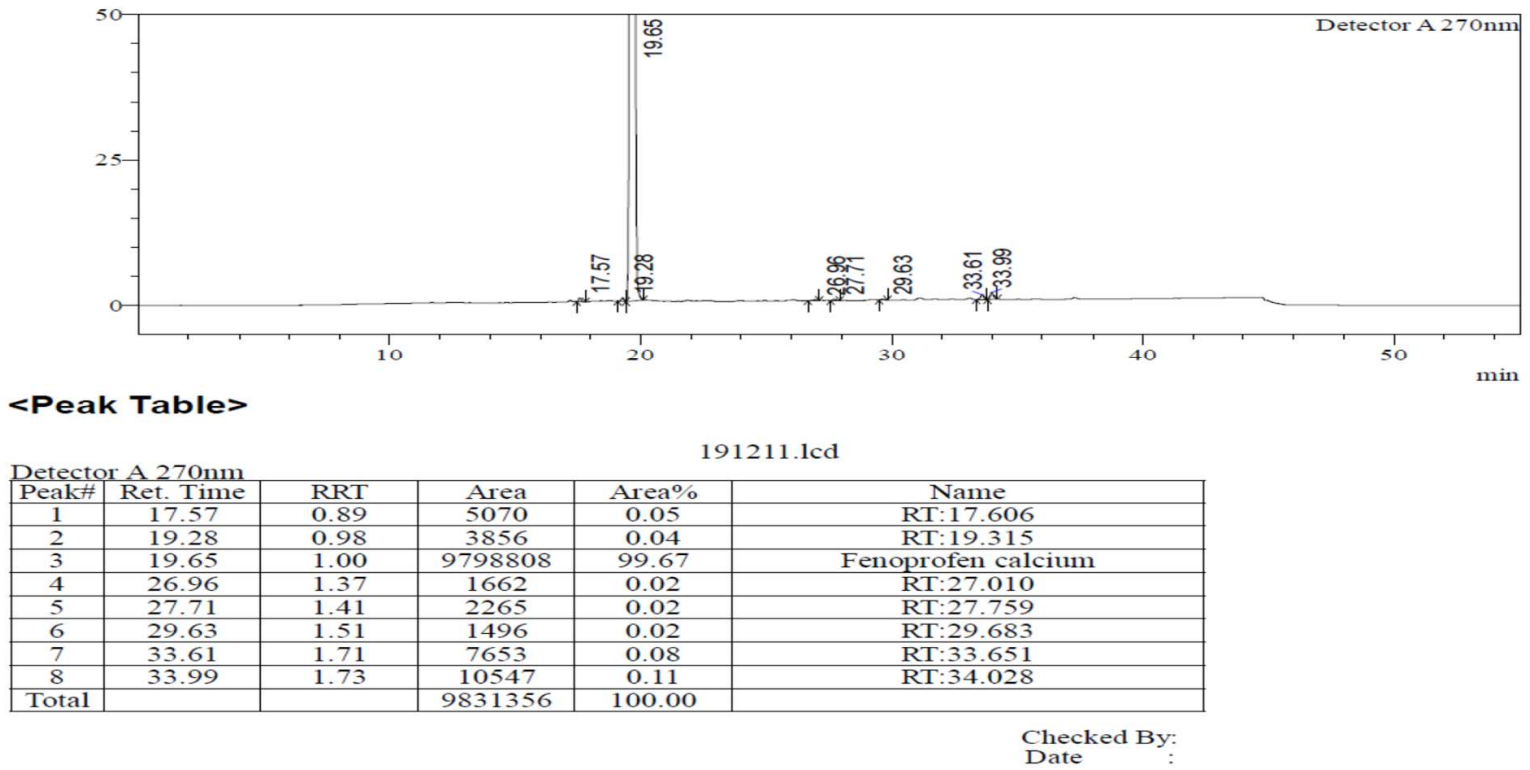

Fig.-6: HPLC Chromatograph of Compound 1

\section{CONCLUSION}

The outcome of this research has been given an innovative green technology for making Fenoprofen calcium dihydrate (an active pharmaceutical ingredient) with promising commercial value at large scale synthesis since none of the literature was reported the current invention process and the salt formation procedure established in green synthetic pathway such as the water used as a solvent. Therefore the process which is reported in this research article is novel, scalable and economic too.

\section{ACKNOWLEDGMENT}

The author thankful to SMS pharmaceuticals Ltd; Management team for supporting the finance and research infrastructure to get this novel research output and special thanks to the AR\&D team for their continuous analytical support.

\section{REFERENCES}

1. Substituted Phenyl Alkanoic Acids and Derivatives Thereof, US 3,600,437 A (1969).

2. G. Kumaraswamy, Nivedita Jena, M. N. V. Sastry, and G. Ramakrishna, ARKIVOC (XV), pp.53-58 (2005).

3. Mariela Agotegaray, Fernanda Gumilar, Monica Boeris, Ricardo Toso, Alejandra Minetti, Bio Med Research International, 2014, 1-9(2014), DOI:10.1155/2014/505987

[RJC-6037/2020] 